Ethics advisors, Centre for Applied Ethics, McGill University Health Centre

\title{
Ethics guidelines and gene editing technology: the challenges of enforceability and legitimacy
}

"Our intelligence creates problems that our intelligence cannot handle. Come back Socrates, we're sorry about the hemlock." Richard Gordon, 1993

Recent advances in genetic technology have given rise to considerable excitement and debate. Genome editing tools such as CRISPR/Cas9 have made modifying the human genome more efficient, accurate, and less expensive. Gene editing presents promise for advancements in human health while simultaneously raising significant ethical concerns about its proper use and potential for misuse (1). For instance, should a line be drawn between genetic therapy and genetic enhancement? If so, where should the line be drawn - and who gets to decide?

One response to the development and implementation of health innovations has been the creation of ethical guidelines. These fall into two broad categories: guidelines for research and development, and guidelines for practice. Research ethics guidelines are particularly effective, as they tend to be highly enforceable through an established ethics oversight system that can put a halt to research projects. For instance, the guidelines of the International Council for Harmonisation of Technical Requirements for Pharmaceuticals for Human Use (ICH) have established consensus on the scientific and ethical conduct of clinical trial research (2). Failure to adhere to the ICH Good Clinical Practice guidelines may jeopardize the registration of the investigational agent under study, possibly costing millions of dollars in lost revenues to product developers.

Ethics guidelines are also important outside the context of research: they provide ethical parameters on complex issues, such as the allocation of resources during pandemics, organ donation, and decision making at the end-of-life. However, these guidelines tend to lack the enforceability mechanisms of research ethics. This can present notable challenges, such as when a product that was submitted to considerable scrutiny and regulation in the research phase enters the market and is used off la- bel. The case of neuro-enhancing drugs is a case in point (3). Thus, research ethics guidelines, however robust, could never fully protect against the use of gene editing technologies for genetic enhancement once these technologies are approved.

In the absence of strict enforceability, ethics guidelines for practice are more likely to benefit from effective uptake if they are perceived to be legitimate, i.e. reflecting a shared acceptance of moral authority. Transparency and public engagement are increasingly accepted as two necessary conditions for ensuring the legitimacy of guidelines. This trend can be observed in the recent joint report of the National Academy of Sciences, National Academy of Medicine, National Academies of Sciences, Engineering, and Medicine, and Committee on Human Gene Editing: Scientific, Medical, and Ethical Considerations (4). By dedicating a full chapter to public engagement, the report sets the stage for a more open public debate.

In addition to transparency and public engagement, articulation of the principles that are to be upheld is essential to the development of effective ethics guidelines. Principles provide a framework for ethical discussion and analysis, which can then help illuminate the implications of specific decisions (5). For example, ethical analysis could look at the ethical implications of the use of gene editing technologies, such as inequity in access and outcome. This analysis need not rely on distinctions between therapy and enhancement. The National Academies' report proposes seven such principles they claim are "universal in nature" and built on established international and national guidelines and norms: 1) promoting well-being; 2) transparency; 3) due care; 4) responsible science; 5) respect for persons; 6) fairness; and 7) transnational cooperation. Following further public debate, these principles could be adopted in ethics guidelines on the use of gene editing technologies.

The need for ethical guidance and oversight in the use of genetic technologies is not new, and it is encouraging that the response to addressing this need 


\section{Health Science Inquiry}

has been proactive, rather than reactive to scandals, as has often been the case in the history of research ethics. Back in 1975, the Asilomar Conference gathered scientists and other stakeholders to discuss the use of genetic technology (6), a conversation that continues to this day. Going forward, the development of effective ethics guidelines for gene editing technologies will depend greatly on their degree of enforceability in the form of regulations and legislation, and on their recognized legitimacy stemming from transparency, public engagement, and principle-based justifications. It is incumbent not only on bioethicists, but also on scientists, policy makers, government officials, and the broader public to explore mechanisms to increase enforceability and legitimacy of future ethics guidelines for gene editing technologies.

\section{References}

1. Sandel, M. The case against perfection: ethics in the age of genetic engineering. Cambridge, Mass: Belknap Press of Harvard University Press, 2007.

2. $\mathrm{ICH}$ expert working group. $\mathrm{ICH}$ Harmonized tripartite guideline: guideline for good clinical practice E6(R1). 1996. Last accessed March 31, 2017. Available at http://www.ich.org/fileadmin/Public_Web_Site/ICH_Products/Guidelines/Efficacy/E6/E6_R1_ Guideline.pdf

3. Maher, B. Poll results: look who's doping. Nature. 2008; 452: 674-675.

4. National Academies of Sciences, Engineering, and Medicine. 2017. Human genome editing: science, ethics and governance. Washington, DC: The National Academies Press. Doi: 10.17226/24623.

5. Beauchamp TL. \& Childress JF. Principles of Biomedical Ethics. $6^{\text {th }}$ ed. New York: Oxford University Press, 2009.

6. Berg, P. Meetings that changed the world: Asilomar 1975:DNA modification secured. Nature. 2008; 455: 290-291.

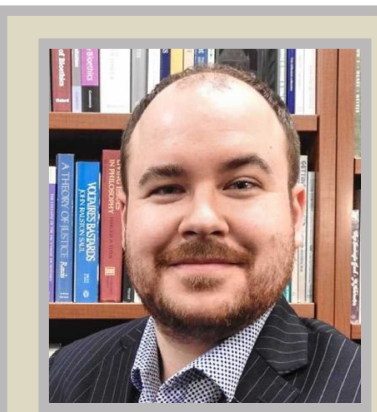

\section{Renaud F. Boulanger}

Renaud is a professional ethicist at the Centre for Applied Ethics, McGill University Health Center (MUHC) and a founding member of the Save the Children UK Research and Evaluation Ethics Committee. He has also provided consultation services to the Bill \& Melinda Gates Foundation and worked for the International Development Research Centre. Outside of his work for the MUHC Research Ethics Board, Renaud writes primarily on the ethics of humanitarian research, turberculosis research, and community engagement. He is an executive editor for BioéthiqueOnline and holds an MSc in Bioethics from McGill University.

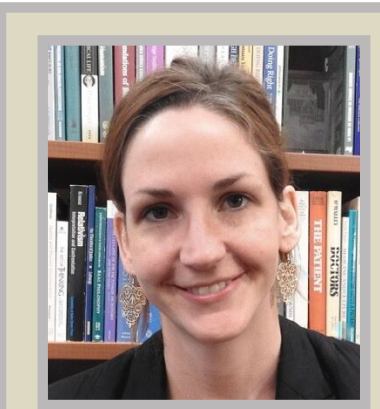

\section{Veronique Fraser}

Veronique has graduate degrees in nursing and bioethics from McGill University and completed a fellowship in clinical and organizational ethics at the Centre for Clinical Ethics and the Joint Centre for Bioethics at the University of Toronto. She has a background in emergency/trauma and community nursing and currently works as a professional ethicist at the Centre for Applied Ethics, McGill University Health Centre (MUHC). She has published on global health ethics and her recent research interests include medical aid in dying and the professionalization of bioethics.

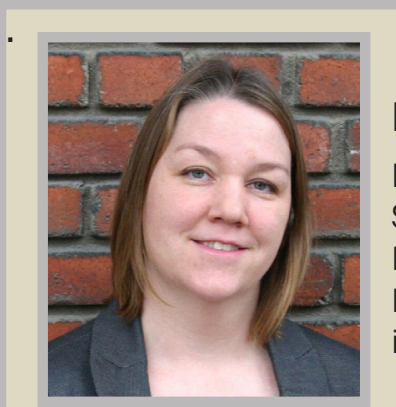

\section{Lori Seller}

Lori has a Masters in Philosophy with a specialization in Biomedical Ethics from McGill University. She has been a professional ethicist at the McGill University Health Center (MUHC) since 2011. Her work involves clinical ethics consultation, teaching, policy development and co-chairing the MUHC Research Ethics Board. Her research interests include end of life issues and medical aid in dying. 